\title{
Correlation of Carotid Artery Intima-Media Thickness with Age, Body Mass Index and Glomerular Filtration Rate in Chronic Kidney Disease Patients
}

\author{
Amir Mohammad Kaiser ${ }^{1}$, Rafi Nazrul Islam², Miliva Mozaffor ${ }^{* 3}$, \\ Salahuddin Feroz ${ }^{4}$, Md. Mustafizur Rahman ${ }^{5}$
}

\begin{abstract}
:
Introduction: Ultrasound measurements of the intima media thickness (IMT) in the carotid arteries is a strong predictor for cardiovascular events both in the general and diseased population. Materials \& Methods: This cross-sectional analytic study was conducted to observe correlation of CIMT with age, body mass index (BMI) and glomerular filtration rate $(G F R)$ in chronic kidney disease (CKD). The study was done in Department of Nephrology, Bangabandhu Sheikh Mujib Medical University (BSMMU), Dhaka, Bangladesh, on 80 chronic kidney disease patients, from July 2014 to June 2015. All the biochemical parameters were measured according to the standard laboratory techniques. Body mass index (BMI) was calculated by person's body weight divided by height. Glomerular filtration rate (GFR) was calculated using the modification of diet in renal disease (MDRD) formula. CIMT measurement was done by duplex study of carotid vessels through high resolution B-mode ultrasound. Results: Mean age of the patients was $36.1 \pm 9.5$ years. 20 $(25 \%), 26(32.5 \%)$ and $34(42.5 \%)$ patients were in CKD stage 3, 4 and 5 respectively. Age, serum creatinine and GFR showed statistically significant difference among stage 3, 4 and 5 CKD patients $(p<0.001)$. However, no difference was evident in BMI and mean CIMT among stage 3, 4 and 5 CKD patients. Significant positive correlations were found between age and CIMT $(r=+0.332 ; p=0.003)$ and BMI and CIMT $(r=+0.294 ; p=0.008)$. However, no significant correlation was evident with estimated glomerular filtration rate $(e G F R)$ and CIMT $(r=-0.181 ; p=0.109)$. Conclusion: Age, serum creatinine and estimated glomerular filtration rate showed statistically significant difference among different stages of CKD patients (stage 3,4 and 5). There were significant positive correlations found in between age and CIMT as well as BMI and CIMT in chronic kidney disease patients, with an exception to GFR and CIMT.

Key words: Carotid artery intima-media thickness, Age, Body Mass Index, Glomerular filtration rate, Chronic kidney disease.
\end{abstract}

Number of Tables: 03;Number of Figures: 03; Number of References: 20; Number of Correspondences: 05.

1. Dr. Amir Mohammad Kaiser

Assistant Professor

Department of Nephrology \& Dialysis Unit

Gonoshasthaya Samajvittik Medical College Hospital,

Savar, Dhaka-1344.

2. Dr. Rafi Nazrul Islam

Senior Medical Officer

Department of Nephrology \& Dialysis Unit

Bangladesh Institute of Research and Rehabilitation in Diabetes, Endocrine and Metabolic Disorders (BIRDEM) Hospital, Dhaka-1000.

*3. Corresponding Author: Dr. Miliva Mozaffor Laboratory Consultant and Assistant Professor Department of Biochemistry

Medical College for Women \& Hospital, Uttara, Dhaka-1230.

Email: miliva17@yahoo.com,

Mobile: +8801732242202 .

4. Dr. Salahuddin Feroz

Junior Consultant (Nephrology)

Sheikh Hasina National Institute of Burn and Plastic Surgery, Dhaka-1000.

5. Dr. Md. Mustafizur Rahman

Assistant Professor

Department of Nephrology

Sheikh Hasina Medical College, Tangail-1900.
Introduction

Patients with chronic kidney disease (CKD) are at high risk for developing cardiovascular disease (CVD) $)^{1,2}$. In 2017, globally CKD resulted in 1.2 million deaths with an additional 1.4 million deaths from cardiovascular disease which were attributable to impaired kidney function ${ }^{3}$. Ultrasound measurements of the intima media thickness (IMT) in the carotid arteries is a non-invasive, yet strong predictor for cardiovascular events both in the general and diseased population ${ }^{4,5}$. Atherosclerosis and arterial calcification can be predicted by age, gender and metabolic status in CKD patients ${ }^{5,6}$. The level of glomerular filtration rate (GFR) is widely accepted as the best overall measure of kidney function in health and disease ${ }^{2}$. The risk of death from cardiovascular disease increases along with the decrease in renal function. A slight decline in glomerular filtration rate in the advanced stage of chronic renal insufficiency results in two- to threefold higher risk of $\mathrm{CVD}^{7}$. For example, in patients under dialysis, this risk is increased from 10 to 100 times in comparison with the general population? ${ }^{7}$ Numerous epidemiological studies in Europe, Americas and Far East have analyzed traditional risk factors like age, body mass index (BMI) and non-traditional risk factor like GFR associated with atherosclerosis development in CKD patients and investigated on correlation of those factors with $\mathrm{CIMT}^{7,8}$. However, the correlation of traditional those cardiovascular risk factors and stages of chronic kidney disease (CKD) with CIMT has not been studied much in our country to date. Hence, the aim of the present study was to observe correlation of 
CIMT with age, body mass index (BMI) and glomerular filtration rate (GFR) on chronic kidney disease (CKD) patients in a tertiary level renal treatment facility in Bangladesh. It is expected that CIMT would be correlated with those CVD risk factors, and the results would predict both possibilities of cardiovascular events and progression to end-stage renal disease, which ultimately could be a useful tool for prediction and helpful to plan early management and prevent further morbidity and mortality in chronic kidney disease patients.

\section{Materials and Methods:}

This cross-sectional analytic study was conducted in Department of Nephrology, Bangabandhu Sheikh Mujib Medical University (BSMMU), Dhaka, Bangladesh, from July 2014 to June 2015. The study population were the patients with chronic kidney diseases, who were admitted into BSMMU Hospital during that period. However, convenient sampling technique was adopted. Finally, a total of 80 patients were selected based on inclusion and exclusion criteria. Inclusion criteria were - age ranging from 18 to 50 years, and only patients of CKD stage 3, 4 and 5 (as defined by KDOQI Clinical Practice Guidelines for Chronic Kidney Disease, $2002)^{2}$. Exclusion criteria were - patients having acute kidney injury, carotid surgery, smokers or alcoholics, or on lipid lowering agents, and having history of ischemic heart disease or stroke. Data collection was done after taking written informed consent from each patient or from his/her legal guardian who fulfilled the criteria. They were evaluated by history, clinical examinations and laboratory investigations as per data collection sheet. The patients were investigated with complete blood count, urine routine examination, serum creatinine and fasting lipid profile, ECG and carotid artery ultrasound. All the biochemical parameters were measured according to the standard laboratory techniques. Body mass index (BMI) is a measure of body fat and was calculated by dividing weight in kilograms by height in meters squared in each patient. Then based on BMI, the patients were categorized as per guideline of WHO Expert Consultation (2004)9. Serum creatinine was measured by alkaline picrate method (Jaffe kinetic assay). Serum creatinine was determined as $\mathrm{mol} / \mathrm{L}$ and converted to $\mathrm{mg} / \mathrm{dl}$ by conversion factor 88.4. With serum creatinine level, Glomerular filtration rate (GFR) was calculated using the Modification of Diet in Renal Disease (MDRD) formula ${ }^{10}$. Carotid artery intimal-medial thickness (CIMT) measurement was done by duplex study of carotid vessels through high resolution B-mode ultrasound technique ${ }^{11}$. High resolution 7-18 MHz linear probe was used and done by a highly skilled sonologist. Normal carotid artery diameter is 4-6 $\mathrm{mm}$. CIMT was measured in its posterior wall, from inner echogenic margin to outer hypoechoic line. CIMT $\leq$ $0.8 \mathrm{~mm}$ in adults was considered as norma ${ }^{12}$. The presence of any atheromatous plaques was also noted. However, the extent of the lesions was not quantified.

The statistical software SPSS (Statistical Package for Social Science) version 22.0 was used for statistical analysis. The results were presented in tables and figures. The quantitative variables were compared using the Unpaired student ' $\mathrm{t}$ ' test and ANOVA test. Pearson's correlation coefficient test was done to find out the value of correlation coefficient using data from graph. The study was approved by the Institutional Review Board (IRB) of Bangabandhu Sheikh Mujib Medical University (BSMMU), Dhaka, Bangladesh.

\section{Results:}

Among 80 patients, $29(36 \%)$ were in $18-30$ age group, 18 were (23\%) 31-40 age group and $33(41 \%)$ were between 41-50 age group; mean age was $36.1 \pm 9.5$ years (Table-I). 51 patients $(64 \%)$ were male and $29(36 \%)$ were female. 20 (25\%), $26(32.5 \%)$ and $34(42.5 \%)$ patients were in CKD stage 3, 4 and 5 respectively. Based on calculated BMI, 52 patients $(65 \%)$ were within the normal weight range, while $16(20 \%)$ were found underweight, $6(7.5 \%)$ were overweight and $6(7.5 \%)$ were obese (Table-II). Age, serum creatinine level and estimated glomerular filtration rate (eGFR) showed statistically significant difference among stage 3,4 and 5 CKD patients $(\mathrm{p}<0.001)$; however, no difference was evident in BMI and mean CIMT (Table-III). Significant positive correlations were found between age and mean CIMT $(\mathrm{r}=+0.332 ; \mathrm{p}=0.003)$ (Fig. 1) and between BMI and mean CIMT $(r=+0.294 ; p=0.008)$ (Fig. 2). However, no significant correlation was evident between estimated glomerular filtration rate (eGFR) and mean CIMT ( $\mathrm{r}=$ $-0.181 ; \mathrm{p}=0.109$ ) (Fig. 3).

Table-I: Age distribution of the study patients $(n=80)$

\begin{tabular}{lcc}
\hline $\begin{array}{l}\text { Age range } \\
\text { (in years) }\end{array}$ & Frequency & Percentage \\
\hline $18-30$ & 29 & 36 \\
$31-40$ & 18 & 23 \\
$41-50$ & 33 & 41 \\
Total & 80 & 100 \\
Mean \pm SD & \multicolumn{2}{c}{$36.1 \pm 9.5$} \\
\hline
\end{tabular}

Table-II: Distribution of the study patients by BMI $\left(\mathrm{kg} / \mathrm{m}^{2}\right)(\mathrm{n}=80)$

\begin{tabular}{lcc}
\hline BMI $\left(\mathrm{Kg} / \mathrm{m}^{2}\right)$ & Frequency & Percentage \\
\hline Underweight (18.5 or less) & 16 & 20.0 \\
Normal weight (18.5-22.99) & 52 & 65.0 \\
Overweight (23-24.99) & 6 & 7.5 \\
Obesity (25 or more) & 6 & 7.5 \\
Total & 80 & 100 \\
\hline
\end{tabular}

Table-III: Clinical and biochemical parameters in different CKD stages $(n=80)$

\begin{tabular}{lllll}
\hline & \multicolumn{3}{c}{ CKD stage } & \\
\cline { 2 - 4 } \multicolumn{1}{c}{ Variables } & $\begin{array}{l}\text { Stage-3 } \\
(\mathrm{n}=20)\end{array}$ & $\begin{array}{l}\text { Stage-4 } \\
(\mathrm{n}=26)\end{array}$ & $\begin{array}{l}\text { Stage-5 } \\
(\mathrm{n}=34)\end{array}$ & P value \\
\hline Age (years) & $39.4 \pm 7.5$ & $40.3 \pm 8.6$ & $30.7 \pm 8.7$ & $<0.001^{*}$ \\
BMI $\left(\mathrm{Kg} / \mathrm{m}^{2}\right)$ & $21.8 \pm 3.2$ & $22.1 \pm 5.2$ & $21.7 \pm 7.4$ & $0.967^{\mathrm{NS}}$ \\
Mean CIMT $(\mathrm{mm})$ & $1.1 \pm 0.2$ & $1.1 \pm 0.1$ & $1.1 \pm 0.3$ & $0.943^{\mathrm{NS}}$ \\
eGFR $\left(\mathrm{ml} / \mathrm{min} / 1.73 \mathrm{~m}^{2}\right)$ & $30.3 \pm 15.0$ & $19.3 \pm 6.6$ & $7.3 \pm 3.0$ & $<0.001^{*}$ \\
Serum creatinine $(\mathrm{mg} / \mathrm{dl})$ & $2.8 \pm 2.2$ & $3.2 \pm 1.0$ & $9.7 \pm 4.6$ & $<0.001^{*}$ \\
\hline
\end{tabular}

ANOVA test was performed to compare the parameters among different stages of CKD. NS = Non-significant; * = Significant at the level of $\mathrm{p}<0.001$. 


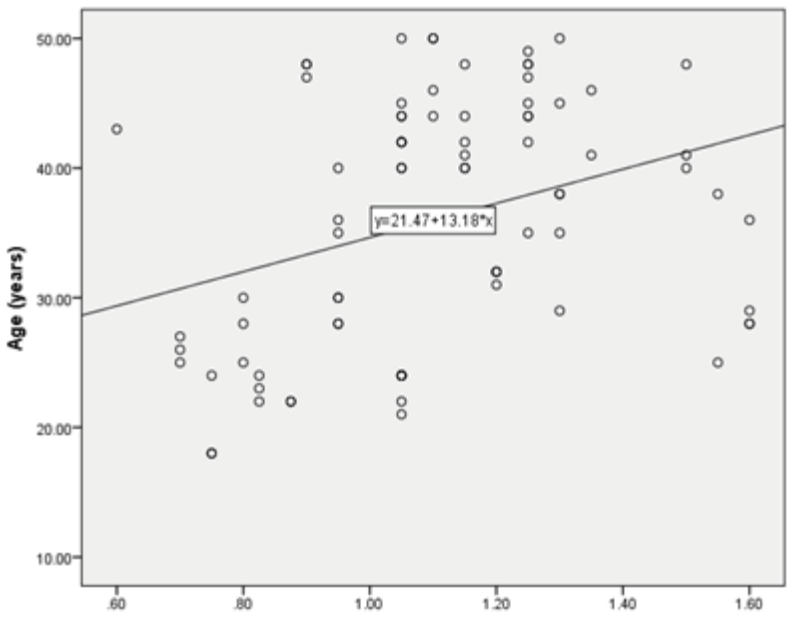

Fig. 1. Scatter diagram showing positive correlation between age and mean CIMT $(r=+0.332 ; p=0.003)$.

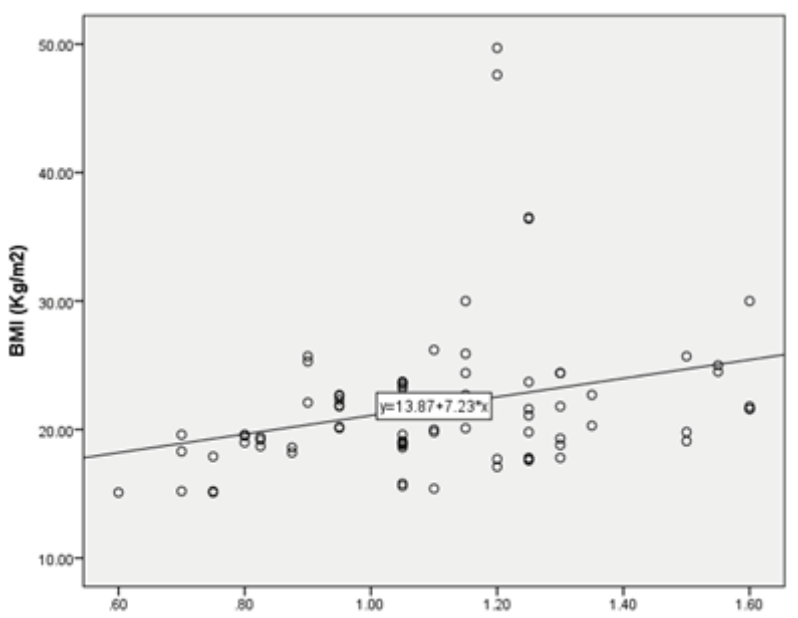

Fig. 2. Scatter diagram showing significant positive correlation between BMI and mean CIMT $(r=+0.294 ; p=0.008)$.

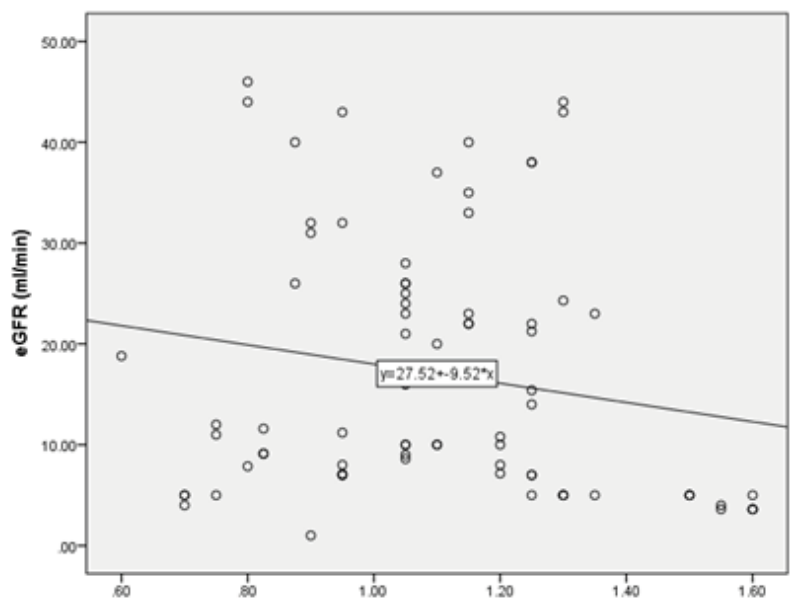

Fig. 3. Scatter diagram showing the correlation between eGFR and mean CIMT $(r=-0.181 ; p=0.109)$.t

\section{Discussion}

The present study showed mean age of the CKD patients $36.1 \pm 9.5$ years. The result is supported by the report of Jha et al. ${ }^{13}$ that showed CKD occurs commonly in young adults between the ages of 20 and 50 years in developing countries of different regions of the world, unlike the comparatively older age groups affected in developed countries. The justification for the younger age of patients with CKD in the developing world include high preponderance of infections/infestations, especially in childhood leading to chronic glomerulonephritis, which is one of the prevailing causes of CKD in South Asia and Sub-Saharan Africa ${ }^{3,13}$. Age contributes to thickening of the arterial wall in all people ${ }^{4}$. However, the present study showed a significant positive correlation between CIMT and age in CKD patients. Similar results were observed in several other studies as reported by Shoji et al. ${ }^{14}(\mathrm{r}=0.270 ; \mathrm{p}<0.001)$, Brzosko et al. ${ }^{15}(\mathrm{r}=0.68 ; \mathrm{p}=0.001)$, Preston et al. ${ }^{16}$, Bevc et al. ${ }^{17}(r=0.589 ; p=0.0001)$, Szeto et $a{ }^{4}{ }^{4}(r=0.373 ; p<0.001)$, Kawamato et al. ${ }^{18}(\mathrm{p}<0.001)$, and later by Olechnowicz-Tietz $\mathrm{S}^{7}$ et al. $(\mathrm{p}=0.008)$, Chhajed et al. ${ }^{8}(\mathrm{r}=0.605 ; \mathrm{p}<0.001)$ and Hinderliter et al. ${ }^{19}(\mathrm{r}=0.61 ; \mathrm{p}<0.001)$. These results reflect that the atherosclerosis increases with age and CKD patients have more vulnerability. Higher CIMT is correlated with obesity-related anthropometric parameters or body fat content including body mass index $(\mathrm{BMI})^{8,20}$. The present study also showed that CIMT positively correlated metabolic status of the patients, i.e. with BMI. Similar association was observed in previous studies done by Brzosko et al. ${ }^{15}$ $(\mathrm{r}=0.50 ; \mathrm{p}=0.02)$, and Chhajed et $\mathrm{al} .{ }^{8}(\mathrm{r}=0.377 ; \mathrm{p}<0.001)$. However, Kawamato et al. ${ }^{18}$ found no correlation between the BMI and CIMT in both men $(\mathrm{r}=-0.055$; $\mathrm{p}=0.253)$ and women $(r=-0.021 ; p=0.616)$. Later, Olechnowicz-Tietz et al. ${ }^{7}$ found that BMI $\geq 30 \mathrm{~kg} / \mathrm{m}^{2}$ was most common among patients with CKD patients of stage 3 and 4 (39.4\% and $60 \%$, respectively), they could not find any correlations though. Similarly, Hinderliter et al. ${ }^{19}$ did not find any correlations $(r=0.05 ; p=0.445)$. The present study showed no significant correlation between CIMT and eGFR. Similar results were observed by Chhajed et al. ${ }^{8}$ ( $\mathrm{r}=-0130$, $\mathrm{p}<0.283)$ and Hinderliter et al. ${ }^{19}(\mathrm{r}=-0.04 ; \mathrm{p}=0.541)$, as they reported that mean CIMT did not directly correlate with eGFR. However, Olechnowicz-Tietz et al. ${ }^{7}$ observed association of CIMT with eGFR (continuous variable) $(p=0.001)$ and with eGFR at advanced CKD $(\mathrm{p}=0.009)$. Similarly, Kawamato et al. ${ }^{18}$ found that correlation between the eGFR and CIMT was significant in both men $(\mathrm{r}=-0.210$; $\mathrm{p}<0.001)$ and women $(r=-0.208 ; p<0.001)$. In our study, the linear regression model showed that factors associated with CIMT were predominantly traditional atherosclerotic risk factors e.g. age and BMI, whereas eGFR was not independently associated with CIMT, which indicates that increased CIMT in patients with CKD might be caused at least in part by those traditional risk factors ${ }^{8}$.

\section{Conclusion:}

In summary, age, serum creatinine and estimated glomerular filtration rate showed statistically significant difference 
among different stages of CKD patients (stage 3, 4 and 5). There were significant positive correlations found in between age and CIMT as well as BMI and CIMT in chronic kidney disease patients, with an exception to GFR and CIMT (as no correlation found). We recommend further studies in the same ethnic population with lager samples and long duration, to determine the mechanism of atherosclerosis in early stages of kidney disease, and the relationship between increase of CIMT and patients' prognosis, with better treatment facility and high technical back-up.

Conflict of Interest: None.

Acknowledgement:

We would like to acknowledge the cooperation provided by Dr. Muhammad Rafiqul Alam, Professor and Chairman, Department of Nephrology, Bangabandhu Sheikh Mujib Medical University (BSMMU), Dhaka, in designing the study, and Dr. A. K. M. Fazlul Bari, Associate Professor, National Institute of Nuclear Medicine \& Allied Sciences (NINMAS), BSMMU Campus, Dhaka, in sonographic investigations.

\section{References:}

1. Liu M, Li XC, Lu L, Cao Y, Sun RR, Chen S, et al. Cardiovascular disease and its relationship with chronic kidney disease. Eur Rev Med Pharmacol Sci. 2014;18 (19):2918-26.

2. National Kidney Foundation. K/DOQI clinical practice guidelines for chronic kidney disease: evaluation, classification and stratification. Am J Kidney Dis. 2002;39(2 Suppl 1):S1-266.

3. GBD Chronic Kidney Disease Collaboration. Global, regional, and national burden of chronic kidney disease, 1990-2017: a systematic analysis for the Global Burden of Disease Study 2017. Lancet. 2020;395(10225):709-33. https://doi.org/10.1016/S0140-6736(19)32977-0.

4. Szeto CC, Chow KM, Woo KS, Chook P, Kwan BCH, Leung $\mathrm{CB}$, et al. Carotid intima media thickness predicts cardiovascular diseases in Chinese predialysis patients with chronic kidney disease. J Am Soc Nephrol. 2007;18 (6):1966-72. https://doi.org/10.1681/ASN.2006101184.PMi d:17494886

5. Lorenz MW, Markus HS, Bots ML, Rosvall M, Sitzer M. Prediction of clinical cardiovascular events with carotid intima-media thickness: a systematic review and meta-analysis. Circulation. 2007;115(4):459-67.

https://doi.org/10.1161/CIRCULATIONAHA.106.628875. PMid:17242284

6. Plantinga Y, Dogan S, Grobbee DE, Bots ML. Carotid intima-media thickness measurement in cardiovascular screening programmes. Eur J Cardiovasc Prev Rehabil. 2009;16(6):639-44.

https://doi.org/10.1097/HJR.0b013e3283312ece. PMid:19752735
7. Olechnowicz-Tietz S, Gluba A, Paradowska A, Banach M, Rysz J. The risk of atherosclerosis in patients with chronic kidney disease. Int Urol Nephrol. 2013;45(6):1605-12.

https://doi.org/10.1007/s11255-013-0407-1.

PMid:23483304 PMCid:PMC3844144

8. Chhajed N, Subhash Chand BJ, Shetty MS, Shetty C. Correlation of carotid intimal-medial thickness with estimated glomerular filtration rate and cardiovascular risk factors in chronic kidney disease. Saudi J Kidney Dis Transpl. 2014;25(3):572-6.

https://doi.org/10.4103/1319-2442.132186. PMid:24821154 9. WHO Expert Consultation. Appropriate body-mass index for Asian populations and its implications for policy and intervention strategies. Lancet. 2004;363(9403):157-63. https://doi.org/10.1016/S0140-6736(03)15268-3.

10. Levey AS, Coresh J, Greene T, Marsh J, Stevens LA, Kusek JW, et al. Expressing the Modification of Diet in Renal Disease Study equation for estimating glomerular filtration rate with standardized serum creatinine values. Clin Chem. 2007;53(4):766-72. https://doi.org/10.1373/clinchem.2006.077180. PMid:17332152

11. Onut R, Balanescu AP, Constantinescu D, Calmac L, Marinescu M, Dorobantu PM. Imaging atherosclerosis by carotid intima-media thickness in vivo: how to, where and in whom? Maedica (Buchar). 2012;7(2):153-62.

12. Simon A, Gariepy J, Chironi G, Megnien JL, Levenson J. Intima-media thickness: a new tool for diagnosis and treatment of cardiovascular risk. J Hypertens. 2002;20( 2):159-69.

https://doi.org/10.1097/00004872-200202000-00001.

PMid:11821696

13. Jha V, Wang AY, Wang H. The impact of CKD identification in large countries: the burden of illness. Nephrol Dial Transplant. 2012;27(Suppl 3):32-8.

https://doi.org/10.1093/ndt/gfs113. PMid:23115140

14. Shoji T, Emoto M, Tabata T, Kimoto E, Shinohara K, Maekawa K, et al. Advanced atherosclerosis in predialysis patients with chronic renal failure. Kidney Int. 2002;61(6):2187-92.

https://doi.org/10.1046/j.1523-1755.2002.00372.x. PMid:12028459

15. Brzosko S, Lebkowska U, Malyszko J, Hryszko T, Krauze-Brzosko K, Mysliwiec M. Intima media thickness of common carotid arteries is associated with traditional risk factors and presence of ischaemic heart disease in hemodialysis patients. Physiol Res. 2005;54(5):497-504.

16. Preston E, Ellis MR, Kulinskaya E, Davies AH, Brown EA. Association between carotid artery intima-media thickness and cardiovascular risk factors in CKD. Am J Kidney Dis. 2005;46(5):856-62.

https://doi.org/10.1053/j.ajkd.2005.07.048. PMid:16253725 
17. Bevc S, Hojs R, Ekart R, Hojs-Fabjan T. Atherosclerosis in hemodialysis patients: traditional and nontraditional risk factors. Acta Dermatovenerol Alp Pannonica Adriat. 2006;15(4):151-7.

18. Kawamoto R, Ohtsuka N, Kusunoki T, Yorimitsu N. An association between the estimated glomerular filtration rate and carotid atherosclerosis. Intern Med. 2008;47(5):391-8. https://doi.org/10.2169/internalmedicine.47.0552.

PMid:18310969

19. Hinderliter A, Padilla RL, Gillespie BW, Levin NW, Kotanko P, Kiser M, et al. Association of carotid intima- media thickness with cardiovascular risk factors and patient outcomes in advanced chronic kidney disease: the kidney disease: the RRI-CKD study. Clin Nephrol. 2015;84 (1):10-20.

https://doi.org/10.5414/CN108494.

PMid:26042415 PMCid:PMC4750113

20. Qu B, Qu T. Causes of changes in carotid intima-media thickness: a literature review. Cardiovasc Ultrasound. 2015;13:46.

https://doi.org/10.1186/s 12947-015-0041-4. PMid:26666335 PMCid:PMC4678459 